\title{
Neuropsychological Evidence for Multiple Implicit Memory Systems: A Comparison of Alzheimer's, Huntington's, and Parkinson's Disease Patients
}

\author{
William C. Heindel, David P. Salmon, Clifford W. Shults, Patricia A. Walicke, and Nelson Butters \\ San Diego VA Medical Center and Departments of Psychiatry and Neurosciences, University of California School of \\ Medicine at San Diego, San Diego, California 92161
}

The performances of patients with dementia of the Alzheimer type (DAT), patients with Huntington's disease (HD), and demented and nondemented patients with Parkinson's disease (PD) were compared on 2 tests of implicit memory that do not require the conscious recollection of prior study episodes: (1) a pursuit-rotor motor learning task and (2) a lexical priming test. The HD patients were found to be impaired on the motor learning but not the lexical priming task, whereas the DAT patients evidenced the opposite relationship on these tasks. The demented, but not the nondemented, PD patients were found to be impaired on both tests of implicit memory. For both the HD and PD patients, deficits on the motor learning task correlated significantly with severity of dementia but not with level of primary motor dysfunction. The noted double dissociation between HD and DAT patients indicates that different forms of implicit memory, all of which are intact in amnesia, are dependent upon distinct neuroanatomic systems. Motor skill learning may be mediated by a corticostriatal system, whereas verbal priming may depend upon the integrity of the neocortical association areas involved in the storage of semantic knowledge. The results for the PD patients suggest that the demented PD patients have endured damage to the neurologic systems subserving both motor learning and lexical priming.

In recent years, there has been increasing interest in the types of memory that are preserved in patients with organic amnesic syndromes. Amnesic patients, who demonstrate profound impairments on recall and recognition tests that make explicit reference to prior episodes, can still perform normally on such "implicit" (Schacter, 1987) memory tests as classical conditioning, skill learning, and verbal priming. Although explicit memory abilities are clearly dependent upon the integrity of the mesial temporal and diencephalic structures damaged in amnesia (Butters and Miliotis, 1985; Squire, 1986), little is known

\footnotetext{
Received Apr. 1, 1988; revised June 30, 1988; accepted July 25, 1988.

This study was supported in part by funds from the Medical Research Service of the Veterans Administration and by NIA Grant AG-05131 to the University of California at San Diego. We wish to thank Ms. Donna McCullough for her help in collecting the data for this study.

Correspondence should be addressed to Nelson Butters, Ph.D., Psychology Service (116B), San Diego VA Medical Center, 3350 La Jolla Village Drive, San Diego, CA 92161

Copyright (C) 1989 Society for Neuroscience $0270-6474 / 89 / 020582-06 \$ 02.00 / 0$
}

about the neuroanatomic substrates underlying implicit memory.

Some clues as to the anatomical basis of implicit memory have emanated from recent studies comparing different forms of dementia. Patients with dementia of the Alzheimer type (DAT) have been reported to be severely impaired on both lexical and semantic priming tasks, while patients with Huntington's disease (HD) were able to demonstrate normal priming ability (Shimamura et al., 1987; Salmon et al., 1988). In contrast, HD patients evidenced little learning on a pursuit-rotor task that was easily mastered by both amnesic and DAT patients (Eslinger and Damasio, 1986; Heindel et al., 1988). This possible double dissociation involving $\mathrm{HD}$ and DAT patients suggests that different implicit memory tasks are mediated by distinct neural systems and that thcse tasks can be used to differentiate some of the so-called "cortical" (e.g., DAT) from "subcortical" (e.g., HD) dementias (Cummings and Benson, 1984).

The purpose of the present investigation is 2-fold. First, an attempt is made to replicate the dissociations between DAT and HD patients on motor learning and lexical priming tasks that were previously reported in separate studies (Shimamura et al., 1987; Heindel et al., 1988; Salmon et al., 1988). The demonstration of this double dissociation with the same patients is critical to the claim that these 2 forms of implicit memory are mediated by distinct neuroanatomic systems.

Second, the present study extends the comparisons of implicit memory in dementia to patients with the dementing and nondementing forms of idiopathic Parkinson's disease (PD). Although there is now general agreement that dementia can be an integral feature of $\mathrm{PD}$, considerable disagreement still exists concerning the underlying nature of the dementia. Several investigators (Albert, 1978; Mayeux et al., 1981a; Huber et al., 1986) have stressed the common features (e.g., preserved language) of the dementias of PD, HD, and other "subcortical" dementias, while others (Alvord et al., 1974; Boller et al., 1980) have suggested that the dementia of PD may be the result of the superimposition of Alzheimer-type changes upon the primary subcortical pathology. The extent to which the dementia of PD can be considered similar to those of DAT and/or HD should be reflected in their performances on the priming and motor learning tasks, respectively. If the dementia of PD is similar to that of DAT, impaired performance on lexical priming combined with intact motor skill learning would be expected. In contrast, if demented PD patients manifest deficient skill learning combined with normal lexical priming, their cognitive impairments would be similar to those of HD patients. 


\section{Materials and Methods}

Subjects. A total of 68 subjects participated in this study: 16 patients with DAT ( 3 males, 13 females), 13 patients with HD ( 9 males, 4 females), 17 patients with $\mathrm{PD}$, and 22 neurologically intact normal control subjects. The control subjects were assigned to either the middleaged (MNC: 2 males, 8 females) or elderly (ENC: 2 males, 10 females) normal control group. The PD patients were separated into demented (DPD: 8 males) and nondemented (NPD: 7 males, 2 females) subgroups on the basis of their performance on the Dementia Rating Scale (DRS) (Mattis, 1976). All demented PD patients obtained DRS scores that were at least 2 SD below the mean of the elderly control subjects (i.e., <134). All 68 subjects were administered both the motor learning and lexical priming tasks.

A diagnosis of DAT was made by a senior staff neurologist according to the criteria developed by the National Insitute of Neurological and Communicative Disorders and Stroke (NINCDS) and the Alzheimer's Disease and Related Disorders Association (ADRDA) (McKann et al., 1984). A number of laboratory tests were performed to rule out various viral, metabolic, or traumatic causes of dementia. Patients with a history of severe head injury, alcoholism, or serious and prolonged psychiatric illness were excluded. To reduce the possibility of including multi-infarct dementias, patients with a score of 5 or grcatcr on the Hachinski scale (Hachinski et al., 1975) were excluded from the DAT group.

The HD patients were diagnosed by a staff neurologist (Dr. Walicke) on the basis of a positive family history for the disease, the presence of involuntary choreiform movements, and the presence of dementia. Their functional capacities were assessed with Shoulson and Fahn's scale (1979), which rates functional disability from 1 (minimal) to 5 (total). Three of the HD patients were rated at functional Stage 2, six at Stage 3, and two at Stage 4. Ten of the HD patients were also rated from 0 (absent) to 4 (severe) on the severity of their choreiform movements. These ratings were made by the staff neurologist without any knowledge of the patients' performance on the implicit memory tests. The mean chorea rating for the HD patients was 2.15 .

The diagnosis of idiopathic PD was made by a staff neurologist (Dr. Shults). Patients with a history of alcoholism, psychiatric illncss, strokc, or other neurologic illness were excluded from this study. All PD patients were rated, using the criteria of the Unified Parkinson's Disease Rating Scale (Fahn et al., 1987), from 0 (absence of symptom) to 4 (greatest severity) on each of the 3 classic Parkinsonian symptoms; i.e., tremor, rigidity, and bradykinesia. The staff neurologist was unaware of the patients' performance on implicit memory tasks at the time these ratings were completed. The demented and nondemented PD groups did not differ significantly in the mean severity of tremor (DPD: 0.75; NPD: 1.00 ), rigidity (DPD: 1.50 ; NPD: 0.83 ), or bradykinesia (DPD: 1.75 ; NPD: 0.94). At the time of testing, all patients were receiving medication (e.g., Sinemet, L-DOPA) for their Parkinsonian symptoms. The mean duration of illness did not differ significantly between the demented (6.4 years) and nondemented (11.0 years) PD groups.

Normal control subjects were either spouses of the patients or paid participants obtained through newspaper advertisements. Volunteers and respondents with a history of alcoholism, drug abuse, learning disabilities, serious neurologic, or psychiatric illness were excluded from this study.

Table 1 shows the mean age, years of education, and DRS score of the 4 patient groups and 2 control groups. The HD patients were significantly younger than the 3 other patient populations [DAT: $t(27)=$ 5.94, $p<0.001$; NPD: $t(20)=2.56, p<0.05$; DPD: $t(19)=4.44, p<$ $0.001]$ but did not differ significantly in age from the middle-aged control subjects. The DAT, DPD, and ENC subjects did not differ significantly in age. The mean age of the NPD group was significantly less than that of the DAT $[t(23)=3.91, p<0.001]$ and DPD $[t(15)=4.13, p<0.001]$ groups, and fell between the ages of the 2 control groups [MNC: $t(17)$ $=2.81, p<0.05$; ENC: $t(19)-3.32, p<0.01]$. The patients with DAT had significantly less education than did the NPD patients $[t(23)=2.86$, $p<0.01]$, DPD patients $[t(22)=3.04, p<0.01]$, and ENC subjects $[t(26)=2.41, p<0.05]$.

All 3 demented patient groups scored significantly lower on the DRS than did their age-matched controls [HD vs. MNC: $t(20)=5.47, p<$ 0.001 ; DAI vs. ENC: $t(26)=9.13, p<0.001$; DPD vs. ENC: $t(18)=$ $7.55, p<0.001]$. The NPD group, in contrast, did not differ significantly on the DRS from either control group and scored significantly higher on the DRS than did the 3 demented patient groups [HD: $t(20)=4.75$, $p<0.001$; DAT: $t(23)=7.70, p<0.001$; DPD: $t(15)=6.28, p<$
Table 1. Psychometric and demographic characteristics of the 6 subject groups

\begin{tabular}{lcccc} 
Group & $n$ & $\begin{array}{l}\text { Age } \\
(\mathrm{yr})\end{array}$ & $\begin{array}{l}\text { Years } \\
\text { of edu- } \\
\text { cation }\end{array}$ & $\begin{array}{l}\text { Dementia } \\
\text { rating } \\
\text { scale }\end{array}$ \\
\hline Middle-aged normal & 10 & 51.3 & 15.3 & 142.4 \\
$\quad$ controls & & $(11.1)$ & $(2.4)$ & $(2.2)$ \\
Elderly normal controls & 12 & 71.3 & 14.8 & 140.3 \\
& & $(6.4)$ & $(2.5)$ & $(2.8)$ \\
Huntington's disease & 13 & 50.8 & 14.1 & 120.6 \\
patients & & $(13.2)$ & $(2.2)$ & $(11.7)$ \\
Alzheimer's disease & 16 & 74.3 & 12.2 & 118.3 \\
$\quad$ patients & & $(8.0)$ & $(3.1)$ & $(8.0)$ \\
Nondemented Parkinson's & 9 & 62.7 & 15.7 & 139.8 \\
$\quad$ disease patients & & $(5.1)$ & $(2.5)$ & $(3.1)$ \\
Demented Parkinson's & 8 & 72.4 & 16.0 & 127.4 \\
$\quad$ disease patients & & $(4.4)$ & $(2.3)$ & $(4.9)$ \\
\hline
\end{tabular}

Mean values \pm SD are given.

0.001]. Finally, the patients with DAT had significantly lower DKS scores than did the DPD patients $[t(22)=2.94, p<0.01]$.

Motor learning task. All subjects were tested individually in a quiet, well-lighted room. Subjects were told to maintain contact between a stylus held in their preferred hand and a small metallic disk $(2 \mathrm{~cm}$ in diameter) on a rotating turntable $(25 \mathrm{~cm}$ in diameter). The turntable could be adjusted to rotate at $15,30,45$, or $60 \mathrm{rpm}$ for a given $20 \mathrm{sec}$ trial. All subjects were tested on 3 series of 8 trials each, with each series separated by approximately $30 \mathrm{~min}$ of other psychometric testing. With in each series, subjects were also allowed a 1 min rest interval between the 4 th and 5 th trials, thereby creating 6 blocks of 4 trials each. The total time on target was recorded for each $20 \mathrm{sec}$ trial.

The first test series was preceded by a block of practice trials to determine the speed of rotation of the turntable. On each successive practice trial, the speed of the turntable was increased. The turntable was then set for the remainder of the subject's testing to that speed which was associated with a score (i.e., time on target) closest to $5 \mathrm{sec}$ out of $20 \mathrm{sec}$ (i.e., $25 \%$ on target). In this manner, the initial level of performance of all subject groups was equated. The mean speed of rotation for each of the 6 subject groups was: $35.8 \mathrm{rpm}$ for the HD group; $46.9 \mathrm{rpm}$ for the DAT group; $48.3 \mathrm{rpm}$ for the NPD group; 45.0 $\mathrm{rpm}$ for the DPD group; $58.5 \mathrm{rpm}$ for the MNC group; and $51.3 \mathrm{rpm}$ for the ENC group.

Lexical priming task. The procedures followed for this task were similar to those described by Salmon et al. (1988). Subjects were shown 10 words (e.g., MOTEL, ABSTAIN), each of which was printed on a separate $3 \times 5$ inch card, and were asked to rate how much they liked each word on a 5 -point scale $(1=$ dislike extremely, $5=$ like extremely). Three additional filler words were placed at the beginning of the list and 2 at the end in order to reduce primacy and recency effects, respectively. After the subjects completed this initial rating of the entire set of 10 words, the examiner requested that they perform a second rating of the same words presented in the same order. The rating scale was drawn on a $3 \times 5$ inch card that remained visible to the subjects during the entire rating task.

Following these 2 presentation trials, subjects were shown 203 -letter word stems (e.g., $M O T, A B S$ ) and were asked to complete each stem with the first word that came to mind. Ten of the stems could be completed using study words, and the other 10 stems were used to assess basclinc guessing rates. The stems used to assess baseline rates for some subjects were used as target items for others. There were at least 10 possible words that could be used to complete each target stem, only one of which was presented for study. The entire stem-completion study/ test procedure was then repeated in exactly the same manner using a different list of 10 words. In this way, stem completion was assessed twice, using 2 different lists of 10 words.

Following the stem-completion test, a third list of 10 target words was presented, and subjects again rated how much they liked each word. After 2 list presentations, the subjects were asked to recall as many of the words as possible. Finally, a fourth 10 -word list was presented in 


\section{PURSUIT ROTOR PERFORMANCE}

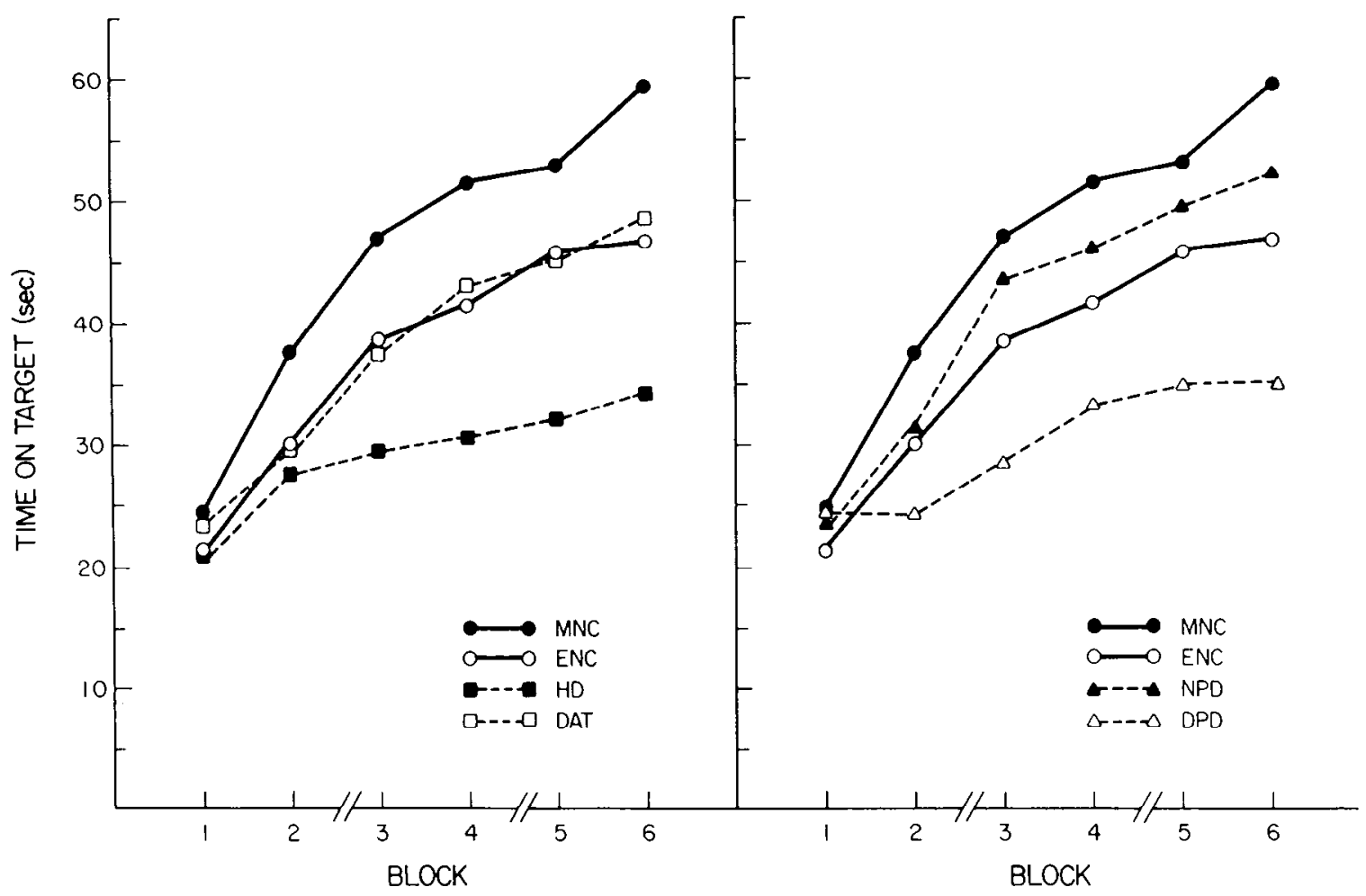

Figure 1. Performance of middle-aged $(M N C)$ and elderly $(E N C)$ normal control subjects, Huntington's disease $(H D)$ patients, patients with dementia of the Alzheimer type $(D A T)$, and demented $(D P D)$ and nondemented $(N P D)$ Parkinson's disease patients on the motor learning task.

the same manner, and subjects were then given a written 2-alternative, forced-choice recognition test. The words used as distractor items in the recognition test for some subjects served as target items for others.

\section{Results}

\section{Motor learning task}

Figure 1 presents the mean total time on target (summed across 4 trials) for the 6 subject groups on each of the 6 test blocks. A 6 (groups) $\times 6$ (blocks) analysis of variance (ANOVA) with repeated measures yielded significant group $[F(5,62)=2.70, p$ $<0.05]$ and block $[F(5,310)=114.92, p<0.001]$ effects, as well as a significant block $\times$ group interaction $[F(5,310)=3.22$, $p<0.001]$. The significant block $\times$ group interaction was analyzed further by using the difference between performance on Block 6 and Block 1 (Block 6 - Block 1) as an indicator of learning across the 6 blocks (see Fig. 2). A 1-way ANOVA yielded a significant group effect $[F(5,62)=5.13, p<0.001]$. Planned comparisons using 2-tailed $t$ tests indicated that although the DAT and NPD groups did not differ significantly from their control groups in the amount they learned on this task, the HD and DPD groups were both significantly impaired relative to their age-matched control groups [HD vs. MNC: $t(21)$ $=4.64, p<0.001$; DPD vs. ENC: $t(18)=2.90, p<0.01]$. Furthermore, the HD and DPD groups both demonstrated significantly less learning than did the DAT [HD: $t(27)=2.07, p$ $<0.05$; DPD: $t(22)=2.18, p<0.05$ ] and NPD [HD: $t(20)=$ $2.70, p<0.05$; DPD: $t(15)=3.00, p<0.01]$ patient groups but did not differ significantly from each other. Group comparisons of the results shown in Figure 1 also indicate that the
6 subject groups did not differ significantly from each other in their initial level of performance on Block 1.

To evaluate whether the motor learning deficits of the $\mathrm{HD}$ and $P D$ patients could be attributed to their basic motor dysfunctions, correlations among motor learning (performance on Block 6 - performance on Block 1), motor impairment (ratings of chorea, bradykinesia, tremor, rigidity), and dementia (scores on the DRS) were calculated. For the HD patients, motor learning correlated significantly with scores on the DRS $(r=0.58, p$ $<0.05$ ) but not with the severity of their choreiform movements $(r=-0.29, p=0.21)$. Similarly, the performance of the PD patients (demented and nondemented patients combined) on the acquisition of the motor skill was significantly correlated with DRS $(r=0.47, p<0.05)$ but not with the severity of their tremor $(r=0.27, p=0.15)$, rigidity $(r=-0.18, p=0.25)$, or bradykinesia $(r=-0.24, p=0.18)$. Thus, motor learning ability in both HD and PD patients appears to be related more to the severity of their dementia than to the severity of their motor dysfunction.

Further analyses also indicated that there was no relationship between rate of motor learning and initial speed of turntable rotation. First, the amount of motor learning displayed by the $6 \mathrm{HD}$ patients with the faster (i.e., 45 and $60 \mathrm{rpm}$ ) rotation speeds did not differ significantly from the amount of learning displayed by the $7 \mathrm{HD}$ patients with the slower (i.e., 15 and 30 $\mathrm{rpm}$ ) rotation speeds (14.42 and $11.35 \mathrm{sec}$, respectively). Second, although the demented and nondemented PD groups differed significantly in their amount of motor learning, the rotation speeds used with these 2 groups were not significantly 


\section{MOTOR LEARNING}

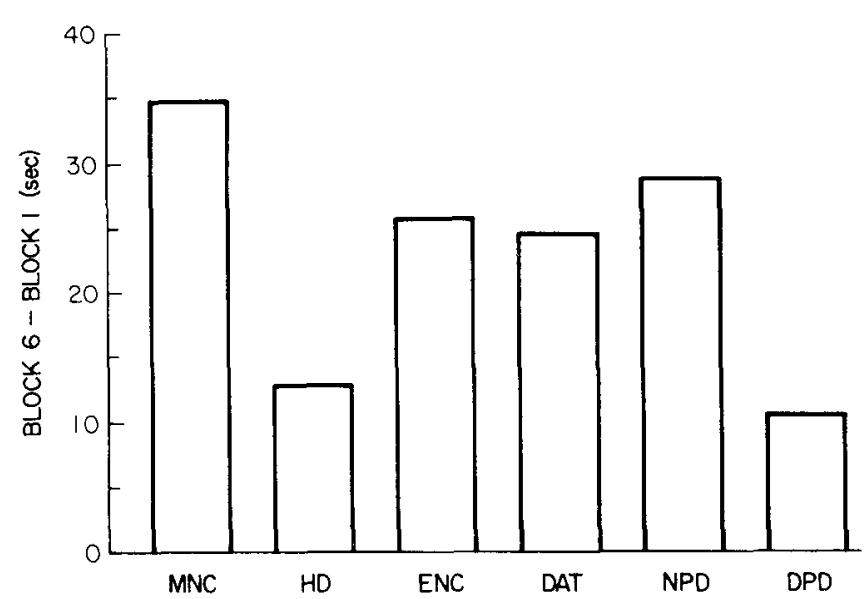

Figure 2. Difference in performance between the last and first test blocks on the motor learning task for middle-aged (MNC) and elderly (ENC) normal control subjects, Huntington's disease $(H D)$ patients, patients with dementia of the Alzheimer type $(D A T)$, and demented $(D P D)$ and nondemented (NPD) Parkinson's disease patients.

different. Third, when the MNC and ENC subjects were first combined and then dichotomized on the basis of rotation speeds (45 rpm: $n=8 ; 60 \mathrm{rpm:} n=14$ ), no significant difference in the amount of motor learning emerged between the groups (28.14 and $30.76 \mathrm{sec}$, respectively). Taken together, these results suggest that adjusting the speed of rotation compensates for motor performance limitations but does not influence the rate of motor learning.

\section{Lexical priming task}

Stem-completion performance and baseline guessing rates of the 6 subject groups are shown in Figure 3. Baseline guessing rates did not differ significantly across groups. Thus, there were no differences in the ability of subject groups to perform the basic task of completing 3-letter stems with words. All patient and control groups exhibited priming scores significantly greater than baseline guessing rates. For statistical purposes, a completion score was calculated by subtracting the baseline guessing rate from the percentage of target words completed for each subject. A 1-way ANOVA on these completion scores yielded a significant group effect $[F(5,62)=6.85, p<0.001]$.

Pairwise comparisons revealed that although the HD and NPD groups did not differ significantly from their control groups in their stem-completion performancc, the DAT and DPD groups were both significantly impaired relative to the elderly control group $[t(26)=4.73, p<0.001 ; t(18)=3.17, p<0.01]$. In addition, the DAT and DPD groups both demonstrated significantly poorer stem-completion performance than did the HD $[t(27)=4.00, p<0.001 ; t(19)=2.64, p<0.05]$ and NPD $[t(23)$ $=4.71, p<0.001 ; t(15)=3.21, p<0.01]$ patient groups, but did not differ significantly from each other.

Figure 4 shows the performances of the patient and control groups on the verbal recall and recognition tests. Analyses of variance revealed significant group effects on both the recall $[F(5,62)=20.98, p<0.001]$ and recognition $[F(5,62)=7.71$, $p<0.001$ ] tests. Pairwise comparisons showed that the HD and DAT groups were significantly impaired on both the recall and

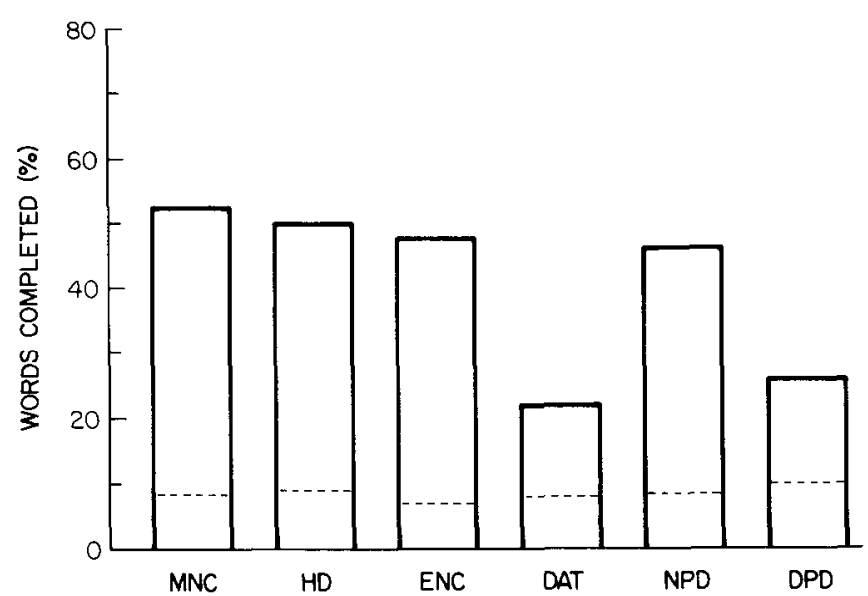

Figure 3. Percentage of word stems completed with previously presented words by middle-aged $(M N C)$ and elderly $(E N C)$ normal control subjects, Huntington's disease $(I I D)$ patients, patients with dementia of the Alzheimer type $(D A T)$, and demented $(D P D)$ and nondemented $(N P D)$ Parkinson's disease patients. The baseline guessing rate of each group is indicated by the broken line.

recognition tests compared with their age-matched control groups [Recall: $t(21)=5.54, p<0.001 ; t(26)=7.73, p<0.001$; Recognition: $t(21)=2.88, p<0.01 ; t(26)=3.68, p<0.01]$. The DPD patients were significantly impaired relative to the elderly controls on the recall but not the recognition test $[t(18)=3.70$, $p<0.01]$, and the NPD patients did not differ significantly from the 2 control groups on either memory task.

On the recall test, the HD and DAT patient groups performed significantly worse than did the NPD group $[t(20)=3.71, p<$ $0.01 ; t(23)=7.90, p<0.001]$, and the DAT group was significantly worse than the $\mathrm{HD}[t(27)=3.15, p<0.01]$ and DPD $[t(22)=2.25, p<0.05]$ groups. On the recognition test, the HD and DAT groups were impaired relative to both the DPD [ $t(19)$ $=2.10, p<0.05 ; t(22)=2.71, p<0.05]$ and NPD $[t(20)=$ $2.87, p<0.01 ; t(23)=3.39, p<0.01]$ groups but did not differ significantly from each other. Finally, the DPD group performed significantly worse than the NPD group on the recall but not on the recognition memory test $[t(15)=3.71, p<0.01]$.

\section{Discussion}

Although previous studies have reported skill learning and verbal priming deficits in $\mathrm{HD}$ and DAT patients, respectively (Martone et al., 1984; Shimamura et al., 1987; Heindel et al., 1988; Salmon et al., 1988), the present findings are the first to demonstrate this double dissociation in a single investigation with the same patient populations. The HD patients were impaired on pursuit-rotor and performed normally on verbal priming, whereas the DAT patients evidenced the opposite relationship on these 2 tasks. Since the HD and DAT groups did not differ significantly on their DRS scores, these dissociations cannot be attributed to differences in the severity of the patients' dementia. Also, the significant correlation between the HD patients' performances on the pursuit-rotor task and on the DRS suggests that their difficulties in acquiring motor skills may be an integral part of their dementia and not a reflection of primary motor deficiencies. 
RECALL RECOGNITION

Figure 4. Percentage of correct responses on the recall and recognition tests for middle-aged $(M N C)$ and elderly $(E N C)$ normal control subjects, Huntington's disease $(H D)$ patients, patients with dementia of the Alzheimer type $(D A T)$, and demented $(D P D)$ and nondemented (NPD) Parkinson's disease patients.

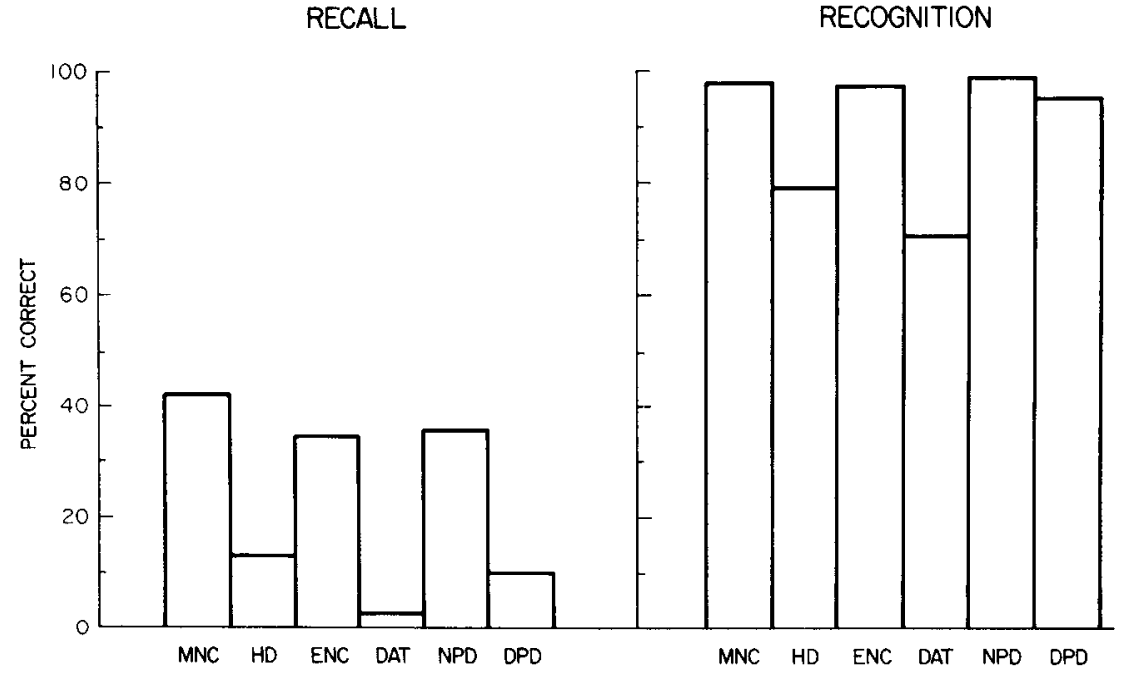

The observed double dissociation between motor skill learning and lexical priming in HD and DAT patients indicates that different forms of implicit memory, all of which are reportedly intact in amnesic patients (see Schacter, 1987; Squire, 1987), are dependent upon distinct neuroanatomical systems. Motor skill learning may be mediated by a corticostriatal system that is severely compromiscd in HD (Bruyn et al., 1979), whereas lexical priming may depend upon the integrity of neocortical association areas damaged in DAT (Brun, 1983; Terry and Katzman, 1983). Support for the proposed skill learning/neostriatum association has been provided by recent studies of motor learning in nonhuman primates (Mishkin and Petri, 1984; Mishkin et al., 1984; Mahut and Moss, 1986).

Although the HD and DAT patient groups displayed different patterns of impairment on the 2 implicit memory tests, both groups were significantly impaired on the recall and recognition tests. These results are consistent with previous reports of explicit memory deficits in HD and DAT patients (Caine et al., 1978; Butters et al., 1986; Butters et al., 1987). It should be stressed that the patterns of implicit and explicit memory performance observed in the present study in no way weaken the general pattern of preserved implicit and impaired explicit memory previously observed in patients with circumscribed amnesic syndromes. To the extent that the brain damage in amnesic patients is restricted to the medial temporal and/or diencephalic regions, one would expect the memory deficit to be restricted to the explicit domain. If, as in the case of demented patients, the damage extends beyond the explicit memory system, one would expect to observe additional deficits in one or more forms of implicit memory.

Unlike the HD and DAT patients, the demented PD patients were impaired on both tests of implicit memory. Since the demented PD patients evidenced less overall dementia (i.e., higher DRS scores) and performed better on recognition memory than did the other 2 demented patient groups, these implicit memory deficits seem even more prominent. Like the HD patients, the PD patients' deficits on motor skill learning were correlated with their degree of dementia but not with the motor symptoms (i.e., rigidity, tremor, bradykinesia) usually associated with the disease. Although the demented and nondemented PD patients did not differ in the severity of their motor symptoms, only the demented PD patients were impaired in the acquisition of the pursuit rotor skill. Apparently, demented PD patients, like HD patients, have a severe skill learning impairment that is at least partially independent of their deficiencies in motor performance.

The impairment of the demented PD patients on the 2 tests of implicit memory suggests that they have endured damage to the previously proposed neurologic systems subserving both motor learning and verbal priming. This conclusion is consistent with the neuropathology associated with PD. First, damage to the corticostriatal system appears to be significantly greater in demented than in nondemented PD patients (Agid et al., 1987). Second, some demented PD patients have been reported to have the cortical neuropathological (Hakim and Mathieson, 1979; Gaspar and Gray, 1984) and neurochemical (Whitehouse et al., 1983; Perry et al., 1985; Cash et al., 1987) changes associated with DAT.

Although the striking behavioral disparity between the demented and nondemented PD patients would seem to support the view that there are 2 distinct forms of PD (Lieberman et al., 1979; Mayeux et al., 1981b), one cannot rule out the possibility that a continuum of cognitive change exists within PD (Quinn et al., 1986). Since the motor signs of PD are not evident until over $70 \%$ of the dopaminergic cells in the substantia nigra are damaged (Bernheimer et al., 1973), the nervous system may compensate for neuronal loss through the hyperactivity of remaining neurons and supersensitivity of target receptors (Schultz, 1982). Conceivably, similar critical thresholds and compensatory mechanisms may be applicable to the dementia of PD.

\section{References}

Agid, Y., M. Ruberg, B. Dubois, and B. Pillon (1987) Anatomoclinical and biochemical concepts of subcortical dementia. In Cognitive $\mathrm{Neu}$ rochemistry, S. M. Stahl, S. D. Iversen, and E. C. Goodman, eds., pp. 248-271, Oxford U. P., Oxford, UK.

Albert, M. L. (1978) Subcortical dementia. In Alzheimer's Disease: Senile Dementia and Related Disorders, R. Katzman, R. D. Terry, and K. L. Bick, eds., pp. 173-180, Raven, New York.

Alvord, E. C., L. S. Forno, J. A. Kusske, R. J. Kauffman, J. S. Rhodes, and C. R. Goetowski (1974) The pathology of parkinsonism: A comparison of degeneration in cerebral cortex and brainstem. In $\mathrm{Ad}$ vances in Neurology, Vol. 5: Second Canadian-American Conference on Parkinson's Disease, F. McDowell and A. Barbeau, eds., pp. 175193, Raven, New York.

Bernheimer, H., W. Birkmayer, O. Hornykiewicz, K. Jellinger, and F. Seitelberger (1973) Brain dopamine and the syndromes of Parkinson and Huntington. J. Neurol. Sci. 20: 415-455.

Boller, F., T. Mizutani, U. Roessmann, and P. Gambetti (1980) Par- 
kinson discasc, dementia, and Alzheimer disease: Clinicopathological correlations. Ann. Neurol. 7: 329-335.

Brun, A. (1983) An overview of light and electron microscopic changes. In Alzheimer's Disease, B. Reisberg, ed., pp. 37-47, Free Press, New York.

Bruyn, G. W., G. Bots, and R. Dom (1979) Huntington's chorea: Current neuropathological status. In Advances in Neurology, Vol. 23: Huntington's Disease, T. Chase, N. Wexler, and A. Barbeau, eds., pp. 83-94, Raven, New York.

Butters, N., and P. Miliotis (1985) Amnesic disorders. In Clinical Neuropsychology, 2nd ed., K. Heilman and E. Valenstein, eds., pp. 403-451, Oxford U. P., New York.

Butters, N., J. Wolfe, E. Granholm, and M. Martone (1986) An assessment of verbal recall, recognition and fluency abilities in patients with Huntington's Discasc. Cortcx 22: 11-32.

Butters, N., E. Granholm, D. P. Salmon, I. Grant, and J. Wolfe (1987) Episodic and semantic memory: A comparison of amnesic and demented patients. J. Clin. Exp. Neuropsychol. 9: 479-497.

Caine, E., R. Hunt, H. Weingartner, and M. Ebert (1978) Huntington's dementia: Clinical and neuropsychological features. Arch. Gen. Psychiatry $35: 377-384$.

Cash, R., T. Dennis, R. L'Heureux, R. Raisman, F. Javoy-Agid, and B. Scatton (1987) Parkinson's disease and dementia: Norepinephrine and dopamine in locus ceruleus. Neurology 37:42-46.

Cummings, J. L., and D. F. Benson (1984) Subcortical dementia: Review of an emerging concept. Arch. Neurol. 41: 874-879.

Eslinger, P. J., and A. R. Damasio (1986) Preserved motor learning in Alzheimer's disease: Implications for anatomy and behavior. J. Neurosci. 6: 3006-3009.

Fahn, S., R. L. Elton, and members of the UPDRS development committee (1987) Unified Parkinson's disease rating scale. In Recent Developments in Parkinson's Disease, Vol. 2, S. Fahn, C. D. Marsden, D. B. Calne, and M. Goldsteing, eds., Macmillan, New York.

Gaspar, P., and F. Gray (1984) Dementia in idiopathic Parkinson's disease. Acta Neuropathol. 64: 43-52.

Hachinski, V. C., L. D. Illiff, E. Zilhka, G. H. DuBoulay, V. L. McAllister, J. Marshall, R. W. R. Russell, and L. Symon (1975) Cerebral blood flow in dementia. Arch. Neurol. 32: 632-637.

Hakim, A. M., and G. Mathieson (1979) Dementia in Parkinson disease: A neuropathologic study. Neurology 29: 1209-1214.

Heindel, W. C., N. Butters, and D. P. Salmon (1988) Impaired learning of a motor skill in patients with Huntington's disease. Behav. Neurosci. 102: 141-147.

Huber, S. J., E. C. Shuttleworth, G. W. Paulson, M. J. G. Bellchambers, and L. E. Clapp (1986) Cortical vs subcortical dementia: Neuropsychological differences. Arch. Neurol. 43: 392-394.

Lieberman, A., M. Dziatolowski, M. Kupersmith, M. Serby, A. Goodgold, J. Korein, and M. Goldstein (1979) Dementia in Parkinson disease. Ann. Neurol. 6: 355-359.

Mahut, H., and M. Moss (1986) The monkey and the sea horse. In The Hippocampus, Vol. 3, R. Isaacson and K. Pribram, eds., pp. 241280, Plenum, New York.
Martonc, M., N. Butters, M. Payne, J. Becker, and D. S. Sax (1984) Dissociations between skill learning and verbal recognition in amnesia and dementia. Arch. Neurol. 41: 965-970.

Mattis, S. (1976) Mental status examination for organic mental syndrome in the elderly patient. In Geriatric Psychiatry, L. Bellack and T. B. Karasu, eds., pp. 77-121, Grune \& Stratton, New York.

Mayeux, R., Y. Stern, J. Rosen, and D. F. Benson (1981a) Subcortical dementia: A recognizable clinical entity. Ann. Neurol. 10: 100-101.

Mayeux, R., Y. Stern, J. Rosen, and J. Leventhal (1981b) Depression, intellectual impairment, and Parkinson disease. Neurology 31:645650.

McKann, G., D. Drachman, M. Folstein, R. Katzman, D. Price, and E. M. Stadlan (1984) Clinical diagnosis of Alzheimer's disease: Report of the NINCDS-ADRDA Work Group under the auspices of Department of Health and Human Services Task Force on $\mathrm{Alz}-$ heimer's Disease. Neurology 34: 939-944.

Mishkin, M., and H. L. Petri (1984) Memories and habits: Some implications for the analysis of learning and retention. In Neuropsychology of Memory, L. R. Squire and N. Butters, eds., pp. 287296, Guilford, New York.

Mishkin, M., B. Malamut, and J. Bachevalier (1984) Memories and habits: Two neural systems. In Neurobiology of Learning and Memory, G. Lynch, J. L. McGaugh, and N. M. Weinberger, eds., pp. 6577, Guilford, New York.

Perry, E. K., M. Curtis, D. J. Dick, J. M. Candy, J. R. Atack, C. A. Bloxham, G. Blessed, A. Fairbairn, B. E. Tomlinson, and R. H. Perry (1985) Cholinergic correlates of cognitive impairment in Parkinson's disease: Comparisons with Alzheimer's disease. J. Neurol. Neurosurg. Psychiatry 48: 413-421.

Quinn, N. P., M. N. Rossor, and C. D. Marsden (1986) Dementia and Parkinson's disease: Pathological and neurochemical considerations. Br. Med. Bull. 42: 86-90.

Salmon, D. P., A. P. Shimamura, N. Butters, and S. Smith (1988) Lexical and semantic priming deficits in patients with Alzheimer's disease. J. Clin. Exp. Neuropsychol. 10:477-494.

Schacter, D. L. (1987) Implicit memory: History and current status. J. Exp. Psychol. Learn. Mem. Cog. 13: 501-517.

Schultz, W. (1982) Depletion of dopamine in the striatum as an experimental model of parkinsonism: Direct effects and adaptive mechanisms. Prog. Neurobiol. 18: 121-166.

Shimamura, A. P., D. P. Salmon, L. R. Squire, and N. Butters (1987) Memory dysfunction and word priming in dementia and amnesia. Behav. Neurosci. 101: 347-351.

Shoulson, I., and S. Fahn (1979) Huntington's disease: Clinical care and evaluation. Neurology 29: 1-3.

Squire, L. R. (1986) Mechanisms of memory. Science 232: 1612-1619.

Squire, L. R. (1987) Memory and Brain, Oxford U. P., New York.

Terry, R. D., and R. Katzman (1983) Senile dementia of the Alzheimer type. Ann. Neurol. 14: 497-506.

Whitehouse, P. J., J. C. Hedreen, C. L. White, and D. L. Price (1983) Basal forebrain neurons in the dementia of Parkinson disease. Ann. Neurol. 13: 243-248. 